\title{
Radiation Interception and Utilization by Chickpea (Cicer arietinum L.) at Different Sowing Dates and Plant Populations
}

\author{
A. Hussain ${ }^{1}$, M. Nawaz and F. M. Chaudhry
}

Department of Agronomy, University of Agriculture, Faisalabad 38040, Pakistan
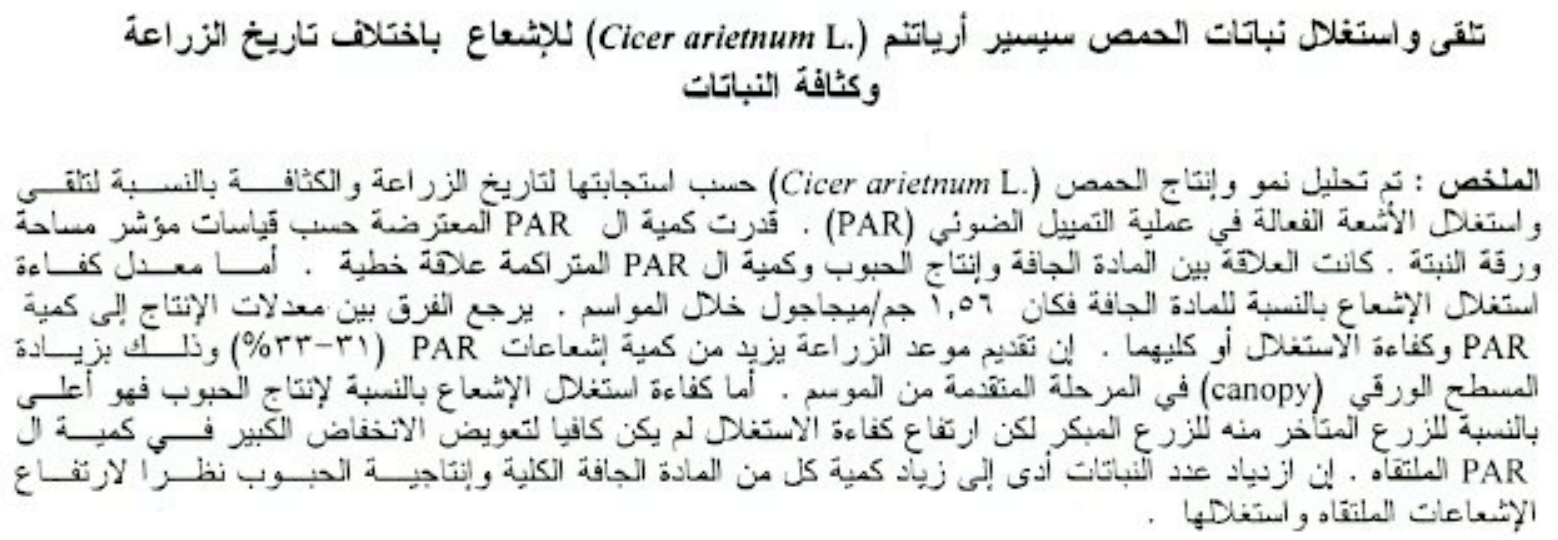

\begin{abstract}
Growth and yield of chickpea (Cicer arietinum L.) in response to sowing date and plant population were analysed in terms of interception and utilization of photo synthetically active radiation (PAR). The amount of PAR intercepted by each treatment was estimated from the measured leaf area index. The relationship between total dry matter, seed yield and accumulated intercepted PAR was linear. The average efficiency of radiation utilization for total dry matter was $1.56 \mathrm{~g} \cdot \mathrm{MJ}^{-1}$ during the seasons. Yield differences between treatments were due to the amount of PAR, its efficiency of utilization or both. Early sowing increased the amount of intercepted PAR (31-33\%) by enhancing the size of the canopy early in the season. The radiation utilization efficiency of seed yield was higher for late sown crops compared to early sown crops. However, the higher efficiency of utilization in late sowing was insufficient to compensate for the significantly lower amounts of intercepted PAR. Higher plant populations increased both the total dry matter and the seed yield due to higher radiation interception and utilization.
\end{abstract}

$\mathbf{T}$ he amount of solar radiation intercepted by a crop is a major determinant of the total dry matter (TDM) produced (Biscoe and Gallagher, 1977). Therefore, analysis of crop growth should consider TDM as a product of the amount of photosynthetically active radiation (PAR) intercepted by the crop, multiplied by an efficiency factor (Monteith, 1977; Gallagher and Biscoe, 1978). Such analyses suggest that the radiation utilization efficiency $(\epsilon)$ is a conservative quantity (Monteith and Elston, 1983), while the amount of radiation intercepted is the variable that determines crop yield. At present, very few studies with chickpea (Hughes et al., 1987; Singh and Sri Rama, 1989; Saxena et al., 1990; Nanda and Saini, 1990) have analysed crop performance in terms of radiation interception and utilization.

This paper examines the relationship between radiation interception and yield of chickpea sown at different times and plant populations.

\section{Materials and Methods}

Two field experiments were conducted to assess the response of chickpea (Cicer arietinum L., cv. C44) to sowing date and plant population. The soil had a sandy clay loam texture and was moderately deep and imperfectly drained.

Both experiments were designed as split plot with four replications. Sowing dates were the main plots and plant populations were the subplots. During Season 1, the treatments were 4 sowing dates (15 October, 5 November, 26 November, 17 December) and 3 plant densities $\left(20,30,40\right.$ plants $\left.\cdot \mathrm{m}^{-2}\right)$. Each subplot was $1.8 \mathrm{~m} \mathrm{x} 12.0 \mathrm{~m}$, and there were 6 rows in

${ }^{1}$ Corresponding author. 
each subplot. In Season 2, the treatments were 3 sowing dates (5 November, 26 November, 17 December) and 3 plant densities $\left(20,40,60\right.$ plants. $\left.\mathrm{m}^{-2}\right)$. Each subplot was $1.5 \mathrm{~m} \times 14.5 \mathrm{~m}$ and there were 6 rows in each subplot.

In each season the experimental site was wetted to field capacity by heavy irrigation ("rouni"). Seedbed preparation was done when the field was under the proper moisture conditions. Although the experiments had different sowing dates, the trial sites were prepared before mid October (Season 1) and early November (Season 2). All the fertilizers at $25 \mathrm{~kg} \mathrm{~N}$ (urea) $\cdot \mathrm{ha}^{-1}$ and $90 \mathrm{~kg} \mathrm{P}$ (single super phosphate; SSP) $\cdot \mathrm{ha}^{-1}$, were applied uniformly to all the plots at the time of seedbed preparation. All plots were sown manually with the help of a dibber,

No irrigation was applied in Season 1. However, one light irrigation (about $20 \mathrm{~mm}$ ) was applied on 28 February in Season 2. Weeds were controlled by hand hoeing during early growth.

SAMPLING: A total of ten harvests were made at two week intervals in each season. A randomly selected area of $1.20 \mathrm{~m} \mathrm{x} 0.40 \mathrm{~m}$ in Season 1 and $1.00 \mathrm{~m} \mathrm{x} 0.50$ $\mathrm{m}$ in Season 2 was harvested from each plot, leaving appropriate borders. The plants were divided into leaves (including rachis), branches and pods (when present). Fresh weights were recorded separately. Sub-samples of 100-200 g of green leaves and branches were oven dried to a constant weight, at $75-80^{\circ} \mathrm{C}$ for determining the dry weights.

A sub-sample of 100-200 $\mathrm{g}$ of green foliage was taken and leaf area was measured with an electronic area meter (Licor, model 3100). The leaf area index (LAI) was calculated as the ratio of the total leaf area to land area. The fraction of radiation intercepted $\left(\mathrm{F}_{\mathrm{i}}\right)$ was estimated from LAI using the exponential attenuation equation suggested by Monteith and Elston (1983):

$$
\mathrm{F}_{\mathrm{i}}=1-\exp (-\mathrm{K} \times \mathrm{LAI})
$$

where $\mathrm{K}$ is an extinction coefficient for total solar radiation (Montieth, 1977). The coefficient is equal to 0.38 for most grain legumes. A K value of 0.47 was used for chickpea, as suggested by Hughes et al. (1987). The PAR was assumed to equal one half $(0.5)$ of the total incident radiation (Szeicz, 1974). Multiplying these totals by the appropriate estimate of $F_{i}$ gave an estimate of the amount of radiation intercepted by a crop canopy (Sa):

$$
\mathrm{Sa}=\mathrm{F}_{\mathrm{i}} \times \mathrm{S}_{\mathrm{i}}
$$

where $S_{i}$ is the total amount of incident PAR.

The radiation utilization efficiency of TDM, $\in \mathrm{T}$, was defined as:

$$
\in \mathrm{T}=\mathrm{TDM} / \Sigma \mathrm{Sa}
$$

A seasonal value of $\in T$ was also estimated from the regression of TDM on accumulated intercepted PAR (Hussain and Field, 1993). This analysis was extended to calculate the efficiency of seed yield ( $\epsilon$ SY).

In Season 1 the final harvest area (3 May) was 1.2 $\mathrm{m} \times 1.0 \mathrm{~m}$. In Season 2 the final harvest area (5 May) was $1.0 \mathrm{~m} \times 1.0 \mathrm{~m}$. The plants were cut at ground level, the number of pods recorded and detached. The pods were threshed by hand. The remaining plant material was separated into leaves, branches, seeds and empty pods. The fresh weight of each fraction was recorded separately. A subsample of each fraction was then oven dried to a constant weight at 75 to $80^{\circ} \mathrm{C}$ for the determination of net above ground dry matter production.

Data analysis was done using the analysis of variance function of the MSTATC/MINITAB statistical computer package. Differences among treatments means were determined using the L.S.D. test when more than two means were found to be significant.

\section{Results}

In Season 1 the total amount of incident PAR received during the growing season was $1345 \mathrm{MJ} \cdot \mathrm{m}^{-2}$ of which only $34 \%$ was intercepted (Table 1). In Season 2 the equivalent figure for the incident PAR was 1382 $\mathrm{MJ} \cdot \mathrm{m}^{-2}$ of which only $25 \%$ was intercepted (Table 2 ).

The amount of PAR intercepted differed significantly between sowing dates. The earlier sowing date ( 15 October) resulted in the interception of more radiation (by about $32-281 \%$ ) than the latter sowing dates in Season 1. The mean values of accumulated intercepted PAR were $680,544,365$ and $240 \mathrm{MJ} \cdot \mathrm{m}^{-2}$ in 15 October, 5 November, 26 November and 17 December, respectively (Table 1). Equivalent figures for Season 2 were 602,275 and $172 \mathrm{MJ} \cdot \mathrm{m}^{-2}$ in 5 November, 26 November and 17 December, respectively (Table 2 ).

Generally higher populations, in both seasons, intercepted significantly more PAR compared to lower populations (Tables 1 and 2). The average values in Season 1, for accumulated intercepted PAR were 409, 441 and $521 \mathrm{MJ} \cdot \mathrm{m}^{-2}$ for 20,30 , and 40 plants $\cdot \mathrm{m}^{-2}$, respectively. Equivalent figures for Season 2 were 272, 347 and $430 \mathrm{MJ} \cdot \mathrm{m}^{-2}$ for $20,40,60$ plants $\cdot \mathrm{m}^{-2}$, respectively. The interaction between sowing date and plant population in Season 2, showed that early sown crops (5 November) markedly enhanced PAR compared to late sown in crops irrespective of plant population. 
TABLE 1

Effect of sowing date and plant population on radiation interception and utilization during Season 1

\begin{tabular}{|c|c|c|c|c|c|c|}
\hline Treatment & $\begin{array}{l}\text { Total incident } \\
\text { PAR }\left(\mathrm{MJ} \cdot \mathrm{m}^{-1}\right)\end{array}$ & $\begin{array}{l}\text { Total intercepted } \\
\text { PAR }\left(\mathbf{M J} \cdot \mathbf{m}^{-1}\right)\end{array}$ & $\begin{array}{c}\text { TDM } \\
\left(\mathrm{g} \cdot \mathrm{m}^{-2}\right)\end{array}$ & $\begin{array}{l}\text { Seed Yield } \\
\left(\mathrm{g} \cdot \mathrm{m}^{-3}\right)\end{array}$ & $\begin{array}{c}\in \mathbf{T} \\
\left(\mathrm{g} \cdot \mathbf{M} \mathbf{J}^{-1}\right)\end{array}$ & $\begin{array}{c}\in \mathbf{S Y} \\
\left(\mathrm{g} \cdot \mathbf{M} \mathbf{J}^{-4}\right)\end{array}$ \\
\hline Sowing date & 1345 & & & & & \\
\hline 15 October & & 680 & 942.82 & 285.82 & 1.47 & 0.44 \\
\hline 5 November & & 544 & 930.14 & 288.97 & 1.74 & 0.53 \\
\hline 26 November & & 365 & 756.00 & 299.91 & 2.10 & 0.86 \\
\hline 17 December & & 240 & 538.67 & 248.15 & 2.35 & 1,08 \\
\hline LSD $5 \%$ & & 117 & 217.33 & NS & NS & 0.24 \\
\hline \multicolumn{7}{|l|}{ Plant population(Plants• $\mathrm{m}^{-2}$ ) } \\
\hline 20 & & 409 & 708.54 & 248.2 & 2.01 & 0.76 \\
\hline 30 & & 441 & 802.75 & 295.75 & 1.95 & 0.78 \\
\hline 40 & & 521 & 864.43 & 298.19 & 1.79 & 0.64 \\
\hline LSD $5 \%$ & & 33 & 105 & 34.82 & NS & 0.11 \\
\hline Mean & & 457 & 791.90 & 280.71 & 1.92 & 0.73 \\
\hline
\end{tabular}

TABLE 2

Effect of sowing date and plant population on radiation interception and utilization during Season 2

\begin{tabular}{|c|c|c|c|c|c|c|}
\hline Treatment & $\begin{array}{l}\text { Total incident } \\
\text { PAR }\left(\mathbf{M J} \cdot \mathrm{m}^{-2}\right)\end{array}$ & $\begin{array}{l}\text { Total intercepted } \\
\text { PAR }\left(\mathbf{M} \cdot \cdot^{-2}\right)\end{array}$ & $\begin{array}{c}\text { TDM } \\
\left(\mathrm{g} \cdot \mathrm{m}^{-2}\right)\end{array}$ & $\begin{array}{c}\text { Seed Yield } \\
\left(\mathrm{g} \bullet \mathrm{m}^{-2}\right)\end{array}$ & $\begin{array}{c}\in \mathrm{T} \\
\left(\mathrm{g} \cdot \mathbf{M J}^{-1}\right)\end{array}$ & $\begin{array}{c}\in \mathrm{SY} \\
\left(\mathrm{g} \cdot \mathrm{MJ}^{-\mathrm{t}}\right)\end{array}$ \\
\hline Sowing Date & 1382 & & & & & \\
\hline 5 November & & 602 & 757.97 & 303.10 & 1.29 & 0.58 \\
\hline 26 November & & 275 & 417.13 & 229.24 & 1.51 & 0.91 \\
\hline 17 December & & 172 & 269.36 & 109.04 & 1.56 & 0.67 \\
\hline LSD $5 \%$ & & 107 & 160.92 & 69.79 & 0.22 & 0.15 \\
\hline \multicolumn{7}{|l|}{ Plant population(plants $\mathrm{m}^{2}$ ) } \\
\hline 20 & & 272 & 404.91 & 180.35 & 1.50 & 0.73 \\
\hline 40 & & 347 & 470.47 & 210.15 & 1.48 & 0.72 \\
\hline 60 & & 430 & 569.11 & 250.87 & 1.40 & 0.71 \\
\hline LSD $5 \%$ & & 38 & 86.43 & 59.43 & NS & 0.17 \\
\hline Mean & & 350 & 481.49 & 213.79 & 1.45 & 0.72 \\
\hline
\end{tabular}

TABLE 3

Interaction between sowing date and plant population affecting radiation interception during Season 2

\begin{tabular}{|c|c|c|c|}
\hline \multirow{3}{*}{$\begin{array}{l}\text { Plant population } \\
\left.\text { (plants } \cdot \mathrm{m}^{-2}\right)\end{array}$} & \multicolumn{3}{|c|}{ Radiation interception $\left(\mathrm{MJ}^{-1-1}\right)$} \\
\hline & \multicolumn{3}{|c|}{ Sowing Date } \\
\hline & 5 Nov. & $26 \mathrm{Nov}$. & $17 \mathrm{Dec}$. \\
\hline 20 & 468 & 228 & 119 \\
\hline 40 & 608 & 272 & 160 \\
\hline 60 & 730 & 324 & 237 \\
\hline LSD 5\% & \multicolumn{3}{|c|}{66} \\
\hline
\end{tabular}

The response was greater at the higher population $(60$ plants $\cdot \mathrm{m}^{-2}$ ) than at the lower populations (Table 3 ).

The accumulated intercepted PAR was linearly related to TDM yield for all treatments in both seasons (Figure 1). The common regression line gave a slope (i.e. efficiency of conversion of PAR to TDM) of 1.56 $( \pm 0.094) \mathrm{g} \cdot \mathrm{MJ}^{-1}$

No significant differences occurred on the efficiency of utilizing radiation among different treatments except in Season 2 when the values for $\in T$ were significantly greater than that for the 5 November sowing. The values for $\in \mathrm{T}$ in the 17 December sowing were smaller in Season 2 compared with Season 1 (i.e. $1.56 \mathrm{~g} \cdot \mathrm{MJ}^{-1}$ compared to $2.35 \mathrm{~g} \cdot \mathrm{MJ}^{-1}$, respectively). The 


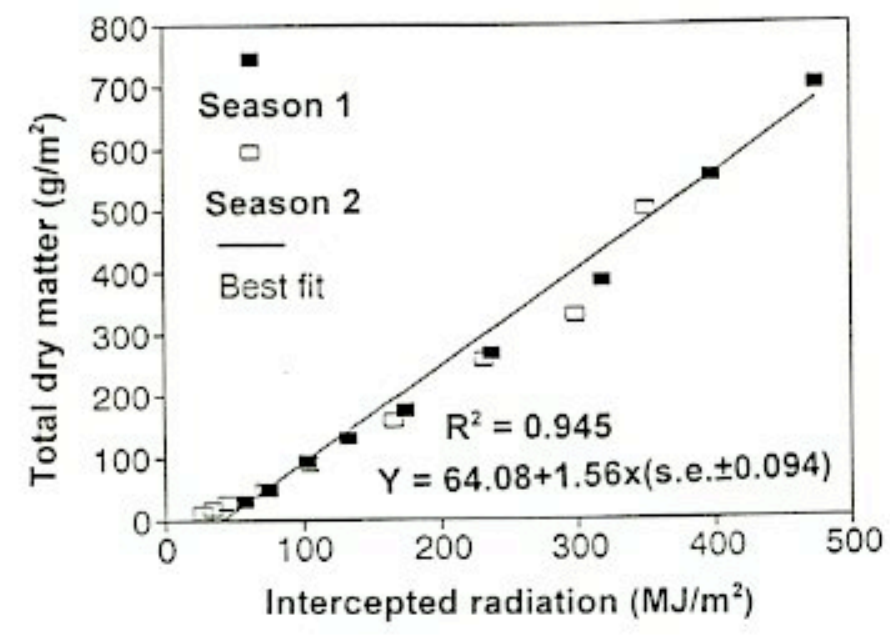

Figure 1. The relationship between intercepted radiation and total dry matter

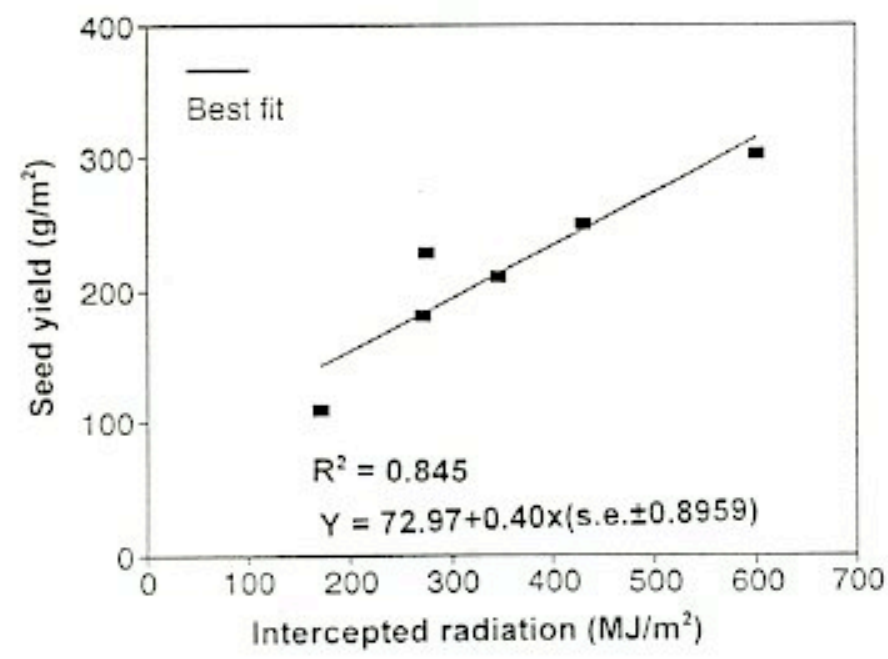

Figure 2. The relationship between intercepted radiation and seed yield in Season 2

mean $\in \mathrm{T}$ values also showed a similar trend ranging for Season 1 and Season 2 from $1.92 \mathrm{~g} \cdot \mathrm{MJ}^{-1}$ to 1.45 $\mathrm{g} \cdot \mathrm{MJ}^{-1}$, respectively (Tables 1 and 2 ).

Regression of seed yield for all treatments in Season 2 on cumulative PAR was also linearly related (Figure 2). The slope of the common lines was 0.40 $( \pm 0.086) \mathrm{g} \cdot \mathrm{MJ}^{-1}$ and the variance was $84.5 \%$.

There were significant differences in the radiation utilization efficiency for seed yield ( $E S Y$ ) among sowing dates in both seasons (Tables 1 and 2). Late sown crops ( 17 December or 26 November) increased $\in S Y$ by about $54 \%$ from $0.44-0.53$ in the 15 October and 5 November sowing to $0.86-1.08 \mathrm{~g} \cdot \mathrm{MJ}^{-1}$ for the 26 November and 17 December sowing, respectively, in Season 1 (Table 1). Similarly, in Season 2, the 26 November sowing also had a higher value of $E S Y$ compared to the 5 November or 17 December sowings, 0.91 vs 0.58 and 0.67 , respectively (Table 2 ).
Plant population did not influence the values of $\in S Y$, except in Season 1 when a population of 20 or 30 plants $\cdot \mathrm{m}^{-2}$ had slightly higher values of $\in S Y$ than a population of 40 plants $\cdot \mathrm{m}^{2}$. The mean values of $\in S Y$ varied from 0.73 to $0.72 \mathrm{~g} \cdot \mathrm{MJ}^{-1}$ in Seasons 1 and 2, respectively (Tables 1 and 2).

\section{Discussion}

Significant differences were found in the amount of PAR absorbed (Tables 1 and 2) between treatments up to the final harvest. Early sowing absorbed $33 \%$ more PAR in Season 1 and $31 \%$ more PAR in Season 2 compared to the late sowing. This was probably due to a longer growth period and a higher plant density. Over the season, similar values of interception in chickpea were reported by Saxena et al. (1990). Our results (Table 3) showed that the magnitude of this response was greater with the higher population. Hughes et al. (1987) also reported more light interception at greater plant density $\left(60\right.$ plants $\left.\cdot \mathrm{m}^{-2}\right)$ than at lower density ( 30 plants $\cdot \mathrm{m}^{-2}$ ).

In our study, the average amount of intercepted PAR was $34 \%$ in Season 1 and $25 \%$ in Season 2, (Tables 1,2). These values are markedly lower than the average value of $40 \%$ reported by Monteith (1977) for different arable crops. Our study demonstrated a linear relationship between yield (TDM, seed yield) and accumulated PAR (Figures 1 and 2). Many workers reported similar results (Hughes et al., 1987; Nanda and Saini, 1990; Saxena et al., 1990). The value for $\epsilon \mathrm{T}$ given by the common regression line (i.e. slope) in Figure 1 was $1.56( \pm 0.094) \mathrm{g} \cdot \mathrm{MJ}^{-1}$. This value compares favorably with those $\left(1.34-2.0 \mathrm{~g} \cdot \mathrm{MJ}^{-1}\right)$ found in the studies done by Hughes et al. (1987); Nanda and Saini (1990) and Saxena et al. (1990) i.e.(1.34-2.0 $\left.\mathrm{g} \cdot \mathrm{MJ}^{-1}\right)$

Few differences were found in the values of $\in \mathrm{T}$ between the treatments, except in Season 2 when the values of $\in \mathrm{T}$ were significantly higher in the late sown crop. These higher values of $\in \mathrm{T}$ in the late sowings were insufficient to compensate for the significantly lower amount of PAR intercepted (Tables 1 and 2), and thus the production of less DM. The relatively smaller values of $\in T$ in the early sowings were probably due to a decline of photosynthetic efficiency of leaves due to age (Woolhouse and Jenkins, 1983).

Seed yield was also linearly related to intercepted PAR (Figure 2). Data in Tables 1 and 2 showed that radiation utilization efficiency of seed yield $(\in S Y)$ was significantly higher in late sown crops compared to early sown crops. These higher values of $\in S Y$ in the late sowing were insufficient to compensate for the significantly lower amount of PAR intercepted, and thus resulted in a lower seed yield (Tables 1 and 2). 


\section{HUSSAIN, NAWAZ AND CHAUDHRY}

Generally a higher plant population increased both the TDM production and seed yield, compared to a lower population, because of higher radiation interception and utilisation (Tables 1 and 2). Hughes et al. (1987) reported similar results. In our study the mean seasonal values of $\in \mathrm{SY}$ were $0.73 \mathrm{~g} \cdot \mathrm{MJ}^{-1}$ in Season 1 and $0.72 \mathrm{~g} \cdot \mathrm{MJ} 1^{-1}$ in Season 2, respectively. Literature is scanty on such comparisons in chickpea. For other grain legumes, the average value of $\in S Y$ varies from 0.72 to $0.90 \mathrm{~g} \cdot \mathrm{MJ}^{-1}$ (Husain et al., 1988).

\section{Conclusion}

Treatments affected crop yield mainly by changing the ability of the canopies to intercept radiation and due to changes in the PAR utilisation efficiency. Considering growth and yield in terms of the amount of radiation crops absorb and the efficiency with which they convert it, DM and seed yield may be physiologically and analytically more relevant than traditional yield component or growth analysis techniques.

\section{References}

Biscoe, P.V, and J.N. Gallagher. 1977, Weather, dry matter production and yield. In: Environmental Effects of Crop Physiology (Eds. J.J. Landsberg and C.V. Cutting) Academic Press. London. pp. $75-100$

Gallagher, J.N. and P.V. Biscoe. 1978. Radiation absorption, growth and yield cereals. J. Agr. Sci. Cambridge. 91:47-60
Hughes, G., J.D.H. Keatinge, P.J.M. Cooper and N.F. Dee. 1987. Solar radiation interception and utilization by chickpea (Cicer arietinum L.) crops in Northern Syria. J. Agr. Sci. Cambridge. 108: 419-424.

Husain, M.M., G.D. Hill and J.N. Gallagher. 1988. The response of field hean (Vicia faba L.) to irrigation and sowing date. 2. Growth and development in relation to yield. J. Agr. Sci. Cambridge. 111:233-254.

Hussain, A. and R.J. Field. 1993. The effect of seedling transplanting on the radiation absorption and utilization in sugar beet. J. Anim. Plant Sci. 3:70-74.

Monteith, J.L. 1977. Climate and efficiency of crop production in Britain. Philosophical Transactions of the Royal Society, London B. 281: 277-294.

Monteith, J.L. and J. Elston. 1983. Performance and productivity of foliage in the field. In: The Growth and Functioning of Leaves (Eds. J.E. Dale and F.L. Milthorpe). Cambridge University Press, London. pp. 499-518.

Nanda, R. and A.D. Saini. 1990. Interception and utilization of solar radiation by chickpea (Cicer arietinum L.). Ann. Agr. Res. 11:2, 177-183.

Saxena, M.C., S.N. Silim and K.B. Singh. 1990. Effect of supplementary irrigation during reproductive growth on winter and spring chickpea (Cicer arietinum) in a Mediterranean environment. J. Agr. Sci. Cambridge. $114: 285-293$

Singh, P. And Y.V. Sri-Rama. 1989. Influence of water deficit on transpiration and radiation use efficiency of chickpea (Cicer arietinum L.). Agr and Forest Metereology. 48: 317-330.

Szeicz, G. 1974. Solar radiation for plant growth. J.Appl Ecol. 11:617-636,

Woolhouse, H.W and G.I. Jenkins. 1983. Physiological responses, metabolic changes and regulation during leaf senescence. In: The Growth and Functioning of Leaves. (Eds. J.E. Dale, and F.L. Milthorpe), Cambridge University Press, pp. 449-487. 